\title{
A Cloud-Based Tool for Integrating Occupational Risk Assessment Within Management Systems for SMEs
}

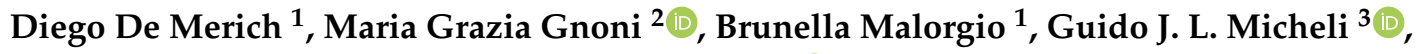 \\ Giusi Piga ${ }^{1}$, Guido Sala ${ }^{3}$ and Fabiana Tornese ${ }^{2, *(D)}$ \\ 1 INAIL-Dipartimento Medicina Epidemiologia Igiene del Lavoro e Ambientale, 00144 Roma, Italy; \\ d.demerich@inail.it (D.D.M.); b.malorgio@inail.it (B.M.); g.piga@inail.it (G.P.) \\ 2 Department of Innovation Engineering, Università del Salento, 73100 Lecce, Italy; \\ mariagrazia.gnoni@unisalento.it \\ 3 Department of Management, Economics, and Industrial Engineering, Politecnico di Milano, 20133 Milano, \\ Italy; guido.micheli@polimi.it (G.J.L.M.); guido.sala@polimi.it (G.S.) \\ * Correspondence: fabiana.tornese@unisalento.it; Tel.: +39-0832-297366
}

Received: 16 September 2020; Accepted: 16 October 2020; Published: 19 October 2020

check for updates

\begin{abstract}
About $67 \%$ of workers employed in the industrial and service sectors in the European Union are currently contracted by Small- and Medium-sized Enterprises (SMEs), which represent the economic heart of the European economy. However, this strength is counterbalanced by a considerably higher overall accident rate compared to Large Enterprises (LEs), and this trend seems to be confirmed worldwide. Moreover, most available tools for risk assessment and occupational health and safety (OHS) management are originally designed to fit the needs of LEs, resulting in a gap for SMEs. Therefore, the effective management of OHS in SMEs has become a crucial issue for researchers, practitioners and policymakers, aiming to improve the social and economic sustainability of small companies. The main purpose of this study is to provide guidelines to implement effective risk assessment processes and integrate them with OHS management systems in SMEs. A literature analysis of risk assessment and OHS management in SMEs highlights the main findings and gaps. Then, the three-phases methodology adopted is presented, outlining the main steps and outputs of the project. Finally, the web-based software tool for OHS risk analysis and management, designed to answer the specific needs of SMEs, is presented.
\end{abstract}

Keywords: occupational health and safety (OHS); small and medium enterprises (SMEs); risk assessment; safety management; web-based software

\section{Introduction}

Traditionally, researchers in the safety field are focusing on designing more effective occupational health and safety management systems (OHSMS) [1]: this is a critical topic especially for Small- and Medium-sized Enterprises (SMEs), with less than 50 employees. Since SMEs represent the heart of the European economy, employing about $67 \%$ of workers of the industrial and service sectors, an effective OHS management in SMEs would be essential to guarantee the social sustainability and economic wealth of European companies. This percentage increases in Italy (raising up to 80\%), with SMEs representing $99.9 \%$ of the total number of companies [2]. Despite their strategic relevance, research shows that OHS management is much more successful in large enterprises (LEs), but it still represents a weakness in SMEs [1]. Furthermore, additional differences could be outlined between Small-scale Enterprises (SEs) - where the organization is based only on two actors, i.e., the owner and workers-and medium enterprises (MEs), where a more formal organization-also in OHS management process [3] -is more widespread. Several factors contribute to this condition. Firstly, 
the effort-defined in terms of time, money as well as competence-available in SMEs for managing safety and prevention is often limited [4]. As a consequence, internal knowledge about OHS is inadequate, as well as the safety culture, including problems and regulations. Secondarily, national legislations could appear complex to be fully applied by SMEs where broad obligations influence heavily their overall efficiency, resulting in more complicated management of legal compliance [5]. In addition, OHS legislation in several countries is based on a self-regulatory approach requiring enterprises to manage health and safety at the workplace but not to provide operational guidelines, thus forcing companies to adopt structured internal risk management systems [6]. Consequently, the limited availability of "tailor-made" tools for SMEs supporting their OHS management and performance evaluation processes is also contributing to the current ineffective condition [7-9], while most SMEs still adopt informal OHSMSs instead of formal ones [10,11].

By analyzing the Italian condition, the current legislation on OHS allows SMEs to adopt a simplified procedure for developing the risk assessment document-known in Italian as "Documento di Valutazione dei Rischi", DVR-following a standardized process: the simplified DVR. A lack in providing to SMEs a simplified standard guideline for supporting both the risk assessment and the management process is still present: thus, a standardized OHS management system is not yet fully in place in Italian SMEs

The objective of this study is to present a web-based software tool for managing both processes-i.e., OHS assessment and management—developed specifically for SMEs: the tool aims to support companies in the safety assessment process using a simplified yet effective processes with management as well as in planning and tracking activities carried out to risk control and management. The tool has been developed through a 3-step methodology presented in Section 3, starting with a combined literature and market analysis that frames the main problems and barriers to OHS risk assessment and management in SMEs, both from a scientific and operative perspective. The methodology consists of a field analysis conducted through surveys and focus groups, which enabled us to identify the needs and peculiarities of SMEs in the Italian context. The results of this phase are reported in a previous study [12]. The paper is structured as follows: Section 2 presents an extensive literature review on the application of OHSMSs in SMEs aiming to point out current criticalities of the context under analysis. The method adopted to develop the software tool is discussed in Section 3, and the results are presented in Section 4, while conclusions are presented in Section 5.

\section{Occupational Health and Safety Management in SMEs: A Literature Analysis}

The literature review performed aimed at highlighting the main features and challenges of current OHS risk assessment and management in SMEs. For this purpose, the scientific databases Web of science and Scopus have been searched using the combined keywords "occupational health and safety" and "small and medium enterprises": conference papers as well as journal publications have been considered. Moreover, results have been integrated through the snowball technique, in order to include other relevant papers. The time period under analysis is from 2000 to 2019: thus, based on these criteria, the web searching has outlined 44 papers. The article selection process included works related to the industrial and service sectors, focusing on OHS systems, performance and assessment. A two-factor clustering analysis has also been proposed: the first one is based on article type, thus five categories are proposed such as literature review, field analysis, simulation modelling, test case and performance evaluation.

Furthermore, all outlined articles have been also classified into five main categories regarding the topic of study in the analyzed problem: the definitions are proposed as follows:

- Group 1: it includes articles investigating barriers and drivers for the successful adoption of OHS interventions in SMEs [7,12-16];

- Group 2: articles reviewing overall features and challenges related to OHS in SMEs [6,8,17-22];

- Group 3: articles proposing new models/approaches proposals for managing OHS in SMEs [23-28]; 
- Group 4: articles proposing an assessment of regional/national legislative bodies as well as conditions studies of OHS management in SMEs [1,10,11,29-45];

- Group 5: articles proposing models to be adopted in risk assessment in SMEs [46-49].

By analyzing the details of the literature review according to the first classification, field analysis is the most popular method adopted for facing the problem in analysis; test case and case studies are the lowest: this is also a first result outlining the lack of operational study in the specific field of research. According to the second categorization, few (6) recent studies have focused on identifying main barriers and drivers related to OHS management (i.e., group 1) in SMEs: the lack of economic resources, dedicated time and effective information is identified as one of the critical factors by Masi and Cagno [7], who also underlined the unsuitability of guidelines to the specific needs of SMEs. Masi et al. [13] state that the OHS intervention process in SMEs tends to often be qualitative and experience-driven, while Garnica and Barriga [14] point out that managers and external stakeholders identify different barriers for OHS implementation beyond the lack of information, the first blaming workers for their lack of awareness and incorrect behaviour, the second citing ineffective management and resource allocation. Micheli et al. [12] outlined that "the excess of external bureaucratic requirements" is one of the main barriers for SMEs. The role of the government in facilitating OHS implementation in SMEs is also highlighted by Wang et al. [15] and Zhang et al. [16], who argue that policy interventions should be improved and simplified. Similar values could be outlined for the third category, which includes six articles containing proposals of new OHS models/approaches. An intervention model has been tested by Walker and Tait [23] on a sample of SMEs in the UK, through a low-cost and low-time demanding approach, confirming that cost and resource effectiveness are appreciated by most of the companies involved. Similarly, Cagno et al. [24] present a model for safety performance designed for SMEs that can enable the identification of possible interventions for improving OHS. Farina et al. [25] analyze the impact of preventive interventions in micro enterprises (MiEs) of the metalworking sector, proposing a safety intervention program and describing its effectiveness in improving the workplace environment safety. Tools for OHS performance evaluation are suggested in two works: Bianchini et al. [26] present the efficacy index, which aims at assessing the effectiveness of an OHSMS, while Tremblay and Badri [27] identify deficiencies and prioritize corrective actions. Finally, Zocca et al. [28] propose a computational tool for SMEs in the agro-food industry.

The second group included literature reviews aiming to point out the features and challenges of OHS assessment and management in SMEs. Hasle and Limborg [17] mention cost-effectiveness of preventive approaches as an important factor for OHS improvement in SMEs, as also confirmed by Cagno et al. [19], while MacEachen et al. [18] explain that the informal workplace environment that often characterizes SEs can alter the apprehension of risk, so subcontracting can complicate the attribution of OHS responsibilities. Floyde et al. [20] present the main challenges and underline that knowledge management and e-learning could generate important benefits in the knowledge-sharing process between workers and managers, which is essential for improving safety management. The role of targeted communication strategies on OHS for SMEs is analyzed by Schulte et al. [21]. Legg et al. [6] and Tremblay and Badri [8] underline that current policy and legislation on OHS, as well as OHS performance evaluation tools, are mostly based on LEs, confirming the need to fit modern OHS interventions to the specific features of SMEs. Nowrouzi-Kia et al. [22] focus on factors related to injuries, concluding that SMEs face more difficulties in managing these factors compared to LEs.

Several regional case studies have been proposed in the literature, mostly based on field analyzes carried out through surveys and/or focus groups, or using secondary data sources from official databases. The relationship between the size of a company and the frequency of accidents in Italy is studied by Fabiano et al. [29], confirming that this frequency increases for SMEs, especially for fatal accidents. Similar outcomes are shown by Micheli and Cagno [30], with accident frequency growing for smaller companies. The Finnish case is analyzed by Lehtinen [31], who points out the importance of networking for SEs in order to promote a safety culture. Analyzing the Spanish context, Arocena and Nunez [10] demonstrate that companies adopting OHSMS have far better performances 
than others when it comes to preventing accidents, results also confirmed by Gopang et al. [32] for Pakistan. Santos et al. [33] highlight that only $26 \%$ of the companies adopting an OHSMS in the Portuguese context choose a certified one (OHSAS 18001); however, these companies reported important improvements in working conditions and internal safety communication. A framework for the implementation of an integrated OHS and Environmental Management System (EMS) is proposed by Jaroenroy and Chompunth [34] in Thailand. Hasle et al. [11] analyze accident attribution in Danish SMEs from the metal and construction sectors, while Cagno et al. [35] study the factors related to OHS in Italian SMEs and how they affect OHS performance. Champoux and Brun [1] study the context in Quebec, pointing out the importance of employees' participation in safety management for its effectiveness, and similar outcomes are also underlined by Surienty [36] for the Malaysian context. Similarly, Diugwu [37] shows that in the UK a fine management of OHS has a positive impact on a company's competitiveness, contributing to improve its image and lowering costs. Bonafede et al. [38] confirm that OHS in Italian SMEs is mostly seen as a law duty entailing a cost, while its value is not perceived by workers. Sinclair et al. [39] underline the key role of intermediaries in the US as facilitators for implementing successfully OHS in SMEs. Boustras et al. [40] analyze safety performance in MiEs in Cyprus, showing that this can be improved introducing a safety policy and supporting the willingness of employees to use personal protection equipment (PPE). Unnikrishnan et al. [41] study OHS implementation in SMEs in India, identifying the main internal barriers in the lack of resources dedicated to safety and little awareness of safety problems, together with a resistance to change. Jahangiri et al. [42] focus on the main problems and conditions of OHS in Iran, while new and emerging risk management is investigated in Spain by Cantonnet et al. [43]. The Spanish context is also studied by Segarra Cañamares et al. [44], who highlight the difficulties related to the integration of occupational risk prevention in the SME management system. Challenges for OHS management in the South African context are analyzed by Mashwama et al. [45], who highlight that the lack of skills, experience and education on safety is among the main criticalities to tackle.

Finally, four works related to risk assessment in SMEs have been analyzed. Dumitrescu and Deselnicu [46] focus specifically on risk factors in manufacturing SMEs, while Sun et al. [47] analyze the chemical sector proposing a set of measurable proactive indicators to assess risk management maturity in SMEs. A new risk assessment model is proposed by Fera and Macchiaroli [48], who also show its reliability through an experimental campaign, while another risk assessment tool is presented by Reinhold et al. [49] and tested on SMEs in Estonia.

In brief, the results outlined by the literature analysis are:

- There is wide awareness in academia about how poorly OHS is currently managed in SMEs, and specific studies confirm this trend in several countries (evidence from Europe, Asia and North America). However, not many attempts to propose new models/approaches for OHS evaluation and management that fit the needs of SMEs exist. In fact, the literature confirms that most of the existing tools and methods for OHS management are originally designed for LEs and are not always suitable for SMEs.

- Several barriers complicate the actual implementation of OHS practices in SMEs. Among these, little resources and time dedicated to promoting a safety culture, ineffective information, unawareness of management and employees, and the internal resistance to change seem to be the most diffused. All of these factors indicate the need for some kind of support to SMEs in the safety management process.

- On the other hand, some drivers can support effective OHS management in SMEs: the legislative pressure raising in several countries, the possibility to increase competitiveness with respect to other companies, as well as the aim to improve internal efficiency and safety.

- Evidence shows that the adoption of OHSMS in SMEs has a positive impact on safety conditions in the workplace, allowing better internal information sharing, and that involving employees in safety management processes is a crucial factor for increasing safety effectiveness. 
- Cost-effectiveness often represents a crucial factor for the management that faces the decision of adopting an OHSMS in SMEs. Therefore, enterprises need to perceive the economic benefits in order to be inclined to adopt a formal management system.

These issues have been evaluated in the methodology development adopted, which is reported in the next section.

\section{Methods}

The methodology adopted to design the tool for supporting OHS risk assessment and management has been developed in three subsequent phases: a flow diagram outlining all the methodological phases and the specific methods adopted is reported in Figure 1.

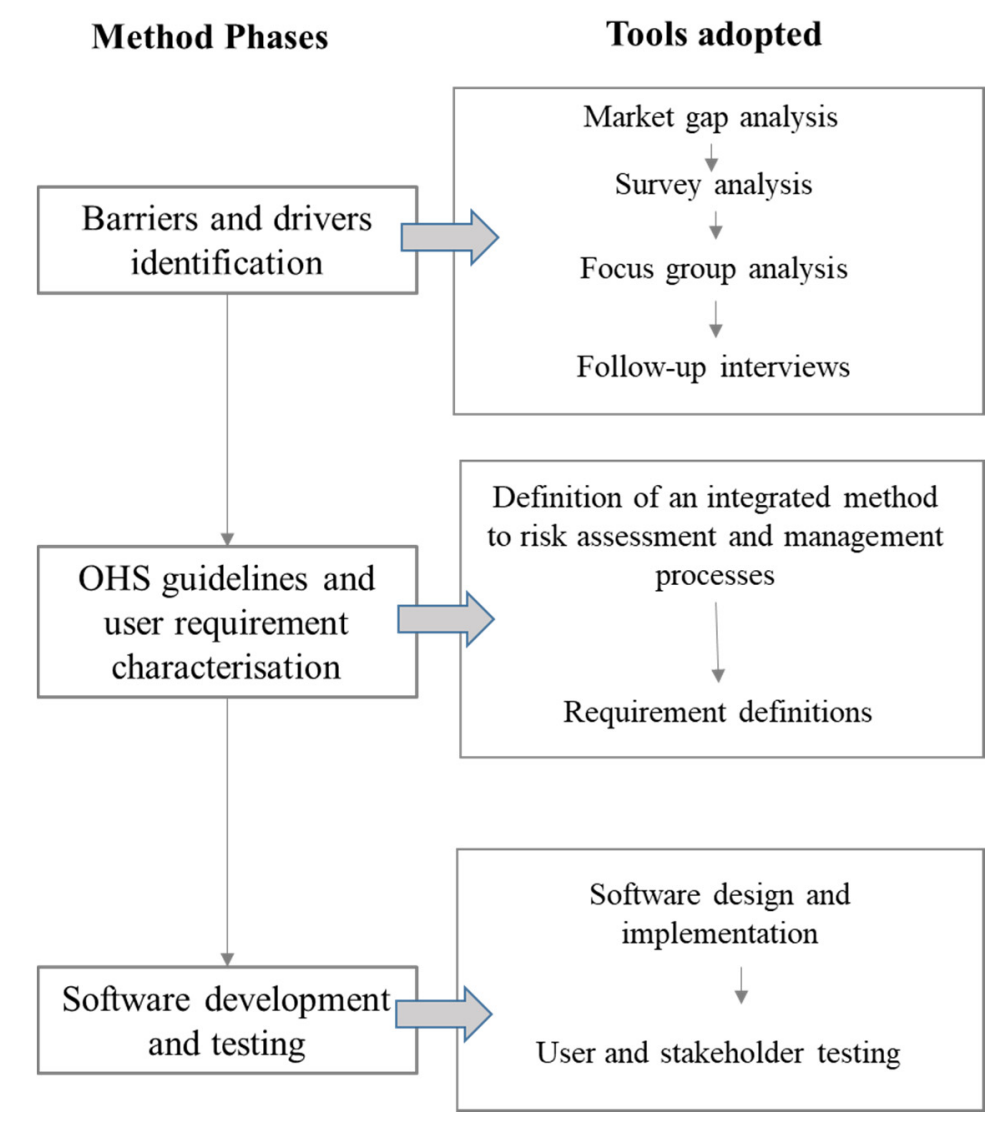

Figure 1. The multiphase methodology adopted.

\subsection{Phase 1: Barriers' and Drivers' Identification}

For the first phase related to the identification of barriers and drivers, next to the literature analysis presented in the previous section, a market gap analysis has been performed, analyzing the available options currently on market for managing OHS in SMEs. The results of this step have been presented in a previous study [50]: in brief, few methodological as well as software-based tools are available to support SMEs in risk assessment development; no one proposed integrated tools for risk assessment and management. Starting from these outcomes, the experience of SMEs located in North Italy has been evaluated through a survey analysis, a focus group and follow-up interviews with the companies involved in the project.

\subsubsection{The Survey Analysis}

The survey was submitted by email to more than 1400 enterprises selected randomly from the Bureau Van Dijk's AIDA (Analisi Informatizzata delle Aziende Italiane) database made available from a 
partner in the project, to investigate their overall knowledge and accessibility of OHSMSs and adoption of software tools. The sample includes Italian companies distributed as follows: $512(34.5 \%$ of the sample) MiEs (1-10 employees), 452 (30.4\% of the sample) semi-MiEs (10-20 employees) and 521 (35.1\% of the sample) SEe and SMEs (20-100 employees), obtaining a response rate of about $8 \%$ (118 answers). Response rate was 5.5\% (82 complete and consistent surveys). The closed format questionnaire was structured in 36 questions divided in 4 main sections: company records, risk assessment and OHSMSs, use of OHS software tools, use of a system for tracking and analyzing injuries and near misses. The sample reflects the project's interests: $63.3 \%$ of companies are metalworking enterprises, $12.5 \%$ are in the wood and paper sectors and $24.2 \%$ are in others. A detailed analysis of the results is reported in a previous paper of the research group [12]. Results confirmed some of the trends highlighted in literature: a poor OHS management in SMEs, the lack of awareness and interest about workplace safety, the need for a tool for OHS easy to use and affordable for small companies. The survey and the focus group were conducted as part of the SOLVO project, BRIC 2016/ID29 funded by INAIL, started on 1 July 2017, and approved by the ethic committee of the Polytechnic of Milan (https://www.polimi.it/ricerca-scientifica/contatti/comitato-etico/).

\subsubsection{The Focus Group and Follow Up Interview Analysis}

A focus group was designed to take place within an association of Italian SMEs, involving a few companies belonging to this organization. The discussion concerned the existing ways of application of a simplified OHSMS and the adoption of software tools aimed at guiding SMEs in the appropriate management of OHS. The focus group participants included both companies with experience in the implementation of management systems, as well as companies dealing with this topic for the first time. The sample of participants also included companies that had experience in OHS software tools for risk assessment, with the aim of understanding their more and less appreciated aspects. Additionally, four firms participating in the survey and the focus group were chosen for a follow-up interview, aiming at analyzing in-depth some of the aspects related to the type of information that can be easily provided for a simplified OHSMS, and the minimum results that a SME expects from an effective OHSMS. Respondents were business owners and/or OHS managers. The discussion involved topics such as the adoption of a software tool for managing a simplified OHSMS, the advantages related to the feedbacks and detailed information that a simplified OHSMS can provide (as an example, data about "near misses").

\subsection{Phase 2: The Operational Guideline Development}

The purpose of this phase was to provide SMEs, especially micro and small companies, with methodological support for developing risk assessment and organizing in an effective way a simplified OHS management system. The basic idea is to provide a simplified but integrated method for developing risk assessment and, next, managing risks, based on the same methodological framework. Results from phase 1 as well as the literature review allowed the identification of the main needs and expectations of SMEs as depicted in Figure 2. In detail, the main functionalities to be provided to SMEs regards:

- A tool for preliminary hazard analysis: the main idea is to provide updated information about the most recurring hazards in a specific company, thus aiming to support a more effective risk assessment process based on real data, usually not available at an individual company level. This information is provided by historical data about injures: the main source is the national database INFORMO, where data (industrial context, injury dynamic and main causes) about mortal injuries occurred in Italian companies are collected by the National Authority. This sample will provide to SMEs updated knowledge about most critical factors outlined in an industrial context similar to theirs. A searching form—based on multiple parameters-allows us to provide these data to the users of the tool;

- A tool for fastly analyzing workplace hazard: the idea is to define a standardized logic to analyze all SME processes and workplaces with an increasing level of details. Thus, the process under 
consideration is analyzed based on a three-level standard schema: at first, hazards defined at plant level are analyzed and, next, hazards at job-shop and working areas, respectively. The aim is to provide a standardized and common way to describe and analyze each specific organization adopted by a single SME from a safety point of view;

- A tool for supporting physical risk analysis: the aim is to use a simplified procedure (compared to the traditional ones based, e.g., on complex risk evaluation), to analyze critical risks for defining prevention and protection activities to be developed. The proposed procedure is based on a simplified logic: if a specific hazard is outlined for the level in analysis-i.e., plant, job-shop and working area-the risk level is defined as "present" thus, allowing a fast risk estimation. Consequently, every time a risk is defined as present, organizational (e.g., training, maintenance) as well as technical (e.g., re-layout, machine modification) interventions, must be adopted to control and manage the risks. Legislative and technical standards could be used to define the most effective actions to be planned. Risks that require a deeper analysis-e.g., manual handling of loads, ergonomics risks-could be evaluated using specific guidelines. The aim is to provide to SMEs a fast tool for risk assessment that provide effective results for their specific conditions;

- Tools for analyzing organizing OHS management system: the tool will provide a simple guideline to organize and apply an OHS management system in SME. Basic pillars are a performance measurement system based on both quantitative indicators and organizational procedures (e.g., audits), a responsibility.

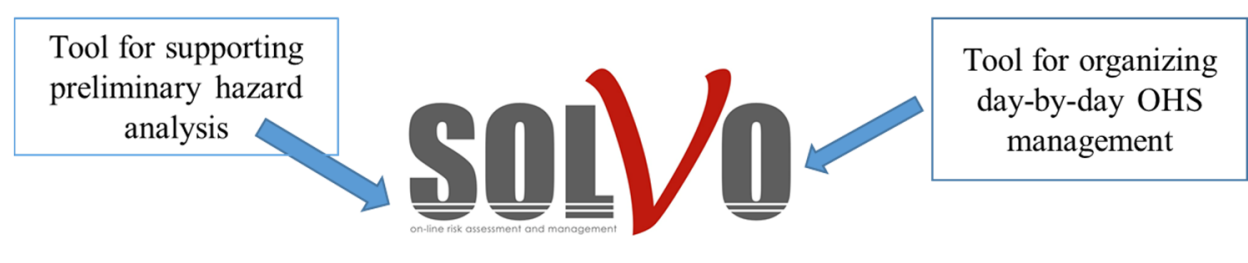

The SOLVO web-platform

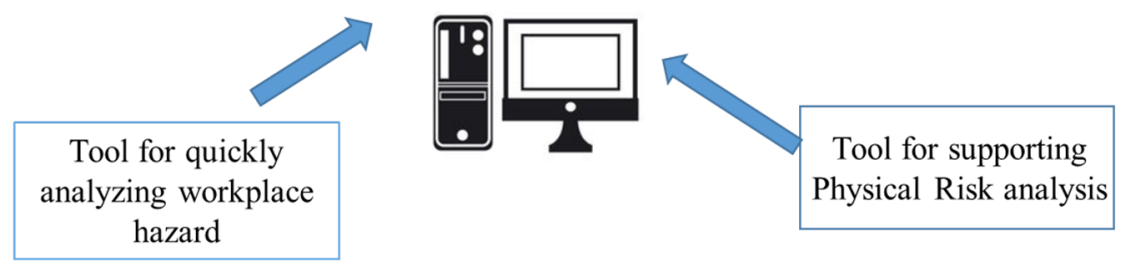

Figure 2. The SOLVO Ecosystem.

This framework-defined as an ecosystem because several different systems interact based on shared data and approaches - served as a starting point to elaborate a prototype web software tool: the SOLVO web platform, named after the project, for supporting SMEs to develop a "simplified" risk assessment document and organize an OHS management system. Results of phase 3-the software development based on guidelines-are described in the following section.

\section{Results: The SOLVO Prototype}

The proposal in this paper is to provide a simple but effective tool to support SMEs in all phases of OHS management from risk assessment to risk control in day-by-day activities. The SOLVO web-platform consists of two interacting modules: the first one is focused on risk assessment and the latter on risk management. The first module includes tools of the SOLVO ecosystem (refer to Figure 2) for quickly analyzing a workplace hazard, for supporting physical risk analysis, and preliminary hazard analysis. The latter includes the tool for organizing day-by-day OHS management processes. A holistic approach has been adopted to integrate the two processes aiming to optimize company resource effort. 
Based on information derived from barriers and drivers identification (see Figure 1), two types of users have been introduced as depicted in Figure 3 for the SOLVO web platform:

- The business owner or the safety manager (indicated through by the Italian acronym ADDL): the person in charge of the risk analysis and assessment process at the workplace level, as well as risk level control in daily operations;

- The safety consultant (defined by the acronym CONS): the person who actually carries out a risk analysis for several companies as a third party-under the authorization of each company employer. The CONS user can visualize data concerning the companies he/she manages, but cannot share them with external users.

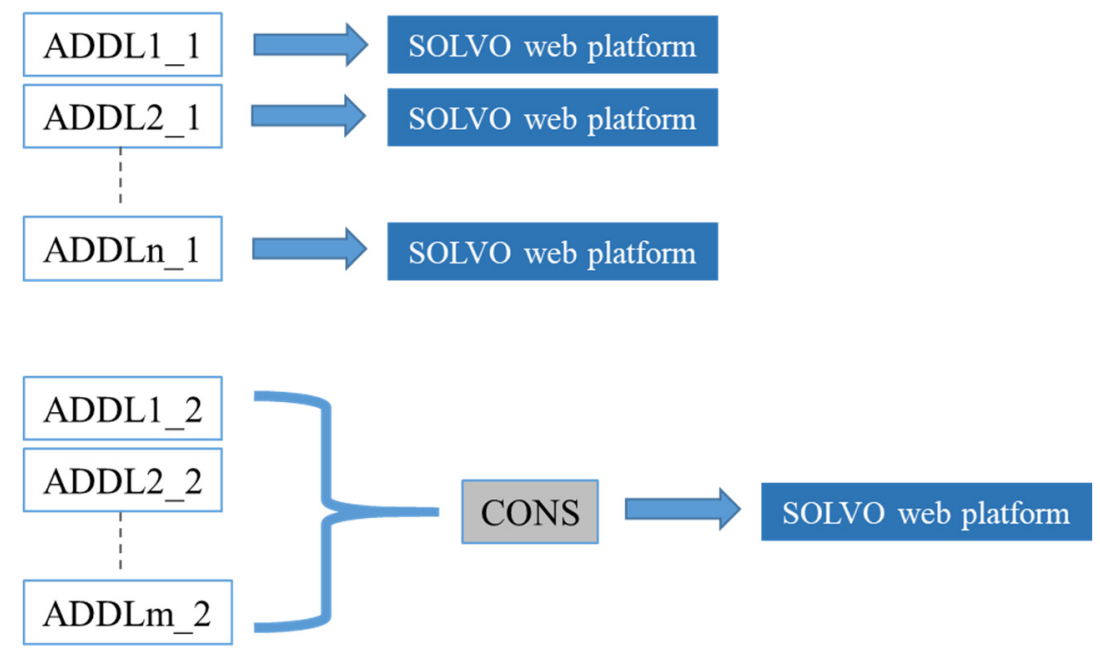

Figure 3. Multi-user scheme.

The cloud platform has been designed in a way that information about a company could be accessed only by the authorized user (only one for a company): no information is provided to anyone.

The risk assessment module, shown in Figure 4, is made up of three sub-modules that the user can compile sequentially, based on the aforementioned simplified DVR allowed by the Italian legislation.

The sub-modules are organized as follows:

1. The company characterization module defines the main data of the workplace that can influence the presence of hazards for workers. The description of the production process and the workplace is defined based on three main levels: company plant site, job-shop and working area. The plant site is the entire building where all activities and processes of the company take place, and is divided into departments (job-shops), which are in turn composed by single working areas. After filling out the company site-level data, the workplace can be composed of several job-shop areas, each one divided into one or more working areas. Next, company employees, equipment and materials (substances) have to be allocated in each of the workplace levels introduced.

2. The hazard analysis module: a simplified and guided method allows the user to identify the hazards based on a set of hazard categories defined for the plant size, the job-shop and working areas previously identified. For each category, a set of hazards typically characterizing the area are defined. The hazard selection is developed starting from these lists. Therefore, the activity of hazard identification consists of the evaluation of the presence or absence of a set of specific hazards. This simplified hazard identification procedure is based on predefined lists of potential hazards and does not require the quantification of each hazard.

3. The module for risk analysis and measurement planning: for each of the hazards identified, some standardized prevention and/or protection measures are identified, which can be related to the training of employees, the adoption of PPE, procedural or technical intervention or periodic 
medical control. Considering also the specific prescription regulated by the current legislation, the user can detail every measure that has to be adopted by the company to mitigate each risk. Next to this, the implementation plan of each intervention, including details such as date and responsibilities, is also defined in order to provide a scheduling for each deadline.

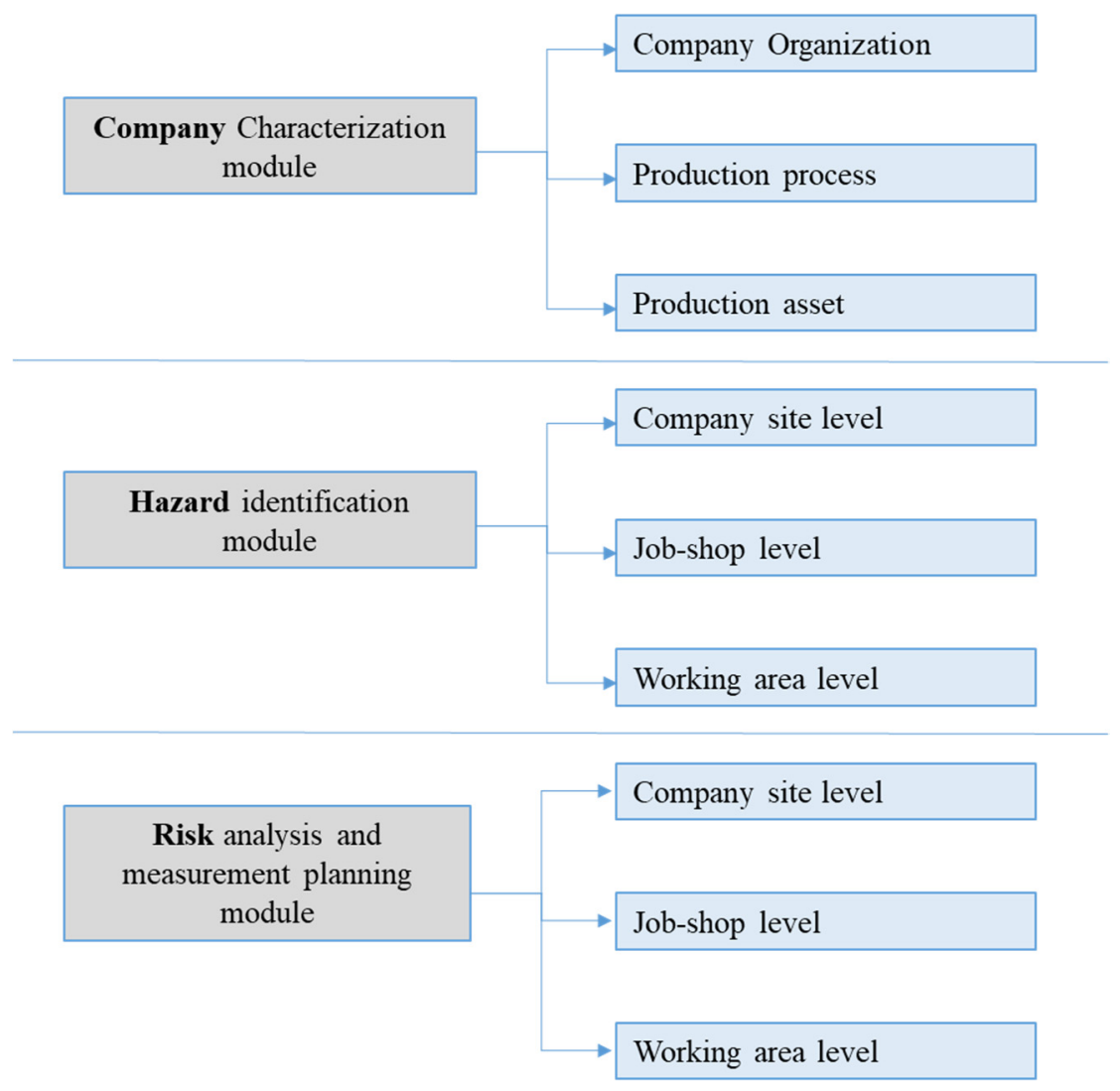

Figure 4. Levels of analysis in the risk assessment module.

The sequence of activities for data entry and analysis in the risk assessment module is in Figure 5.

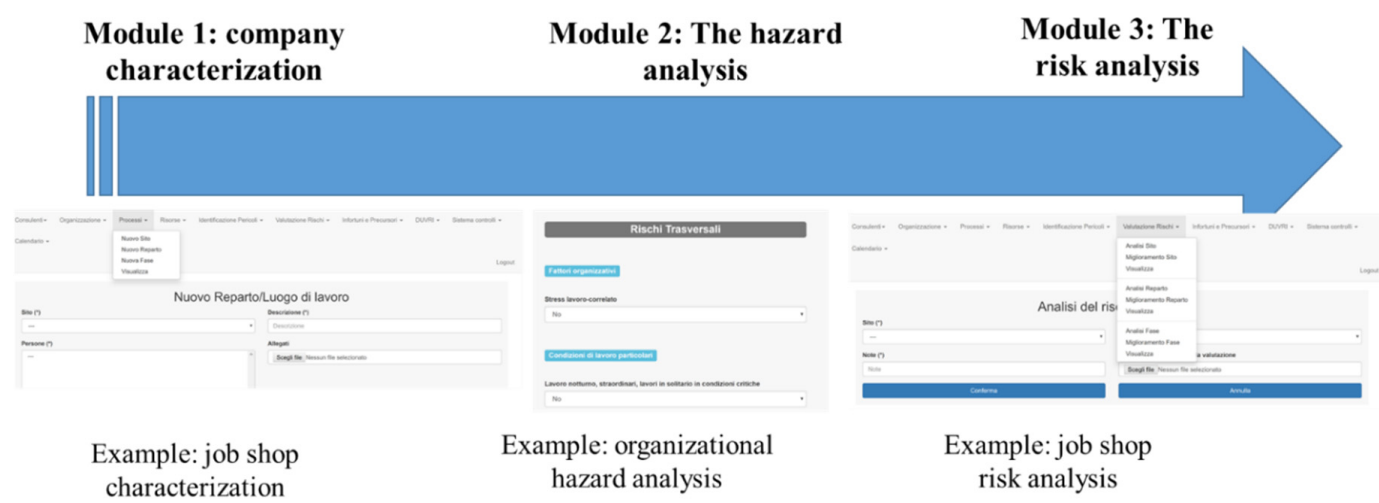

Figure 5. Sequential activities to be developed in the Risk assessment module.

The organizational safety management module is composed of four sub-modules with the following functions:

- a planning module;

- a collection module for injury and precursor (near-miss) events; 
- a module for supporting internal audit and safety control;

- a module for supporting the company in managing documents for external procurement risk analysis process.

In Figure 6, the web-based tool is proposed with all its functionalities.

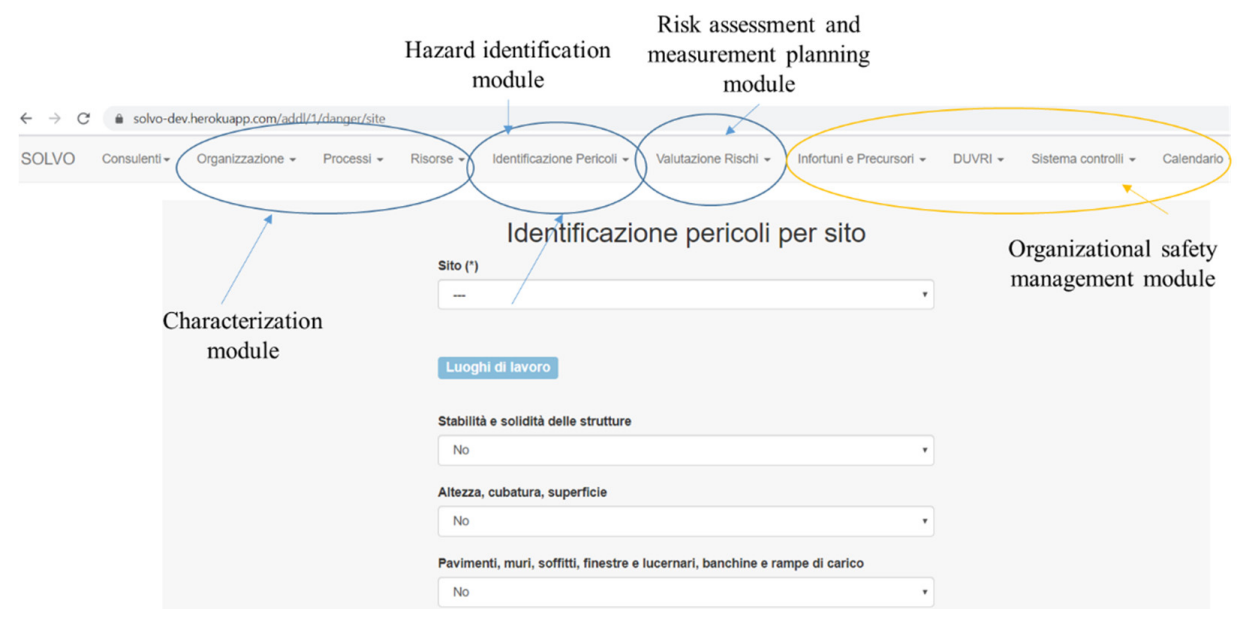

Figure 6. The SOLVO web-based tool.

In this phase related to safety management, the most critical processes and activities for the company can be monitored, with the possibility to track near misses, which can be extremely useful for building experience and preventing future accidents, helping to improve the safety culture and performance of the workplace [51].

\section{Conclusions}

Despite the relevance of SMEs in the European economy, several difficulties related to OHS management for these companies have been reported in the literature, and acknowledged by policy and practitioners, and their great economic potential is threatened by the inefficiency of safety management intervention processes, intensified by the recognized lack of tools designed for their specific needs. To deal with this problem, a few researchers proposed innovative ways to manage OHS in SMEs, but an OHSMS specifically designed for SMEs is still missing since most of the commercial tools available are designed for LEs and provide some kind of support to SMEs just for risk assessment. This work is an attempt to answer this need, proposing a framework for risk assessment and OHS management in SMEs, on which a web-based software tool for safety management is based.

The main innovative features of this approach are the following:

- it proposes a tool fitting the specific needs of SMEs, designed starting from an accurate field analysis to meet their necessities and expectations, which can support them not only in the phase of risk assessment (which is the only one strictly regulated by Italian legislation), but also in other safety management activities which are usually optional for SMEs, contributing to improving management and workers' awareness and information sharing, enhancing prevention and safety conditions in the workplace.

- the cost-effectiveness of the tool: the project allowed the design and test of a web-based open-source software based on the framework elaborated, which is integrated with institutional databases from INAIL and can support SMEs, on one side facilitating the risk assessment process and the production of the DVR, on the other side enabling OHS management activities and promoting the diffusion of a safety culture. 
- The integration with institutional databases and the support from INAIL can also represent an appealing factor for SMEs, which are facilitated to comply with the current Italian legislation on safety management.

The proposed tool has been developed for Italian SMEs: several parts (e.g., hazard categorizations) are typical of the Italian legislation, which might be a limitation of the study; yet, the overall organization of the tool could be easily adapted to other countries with low computational effort. A test activity has been done by involving in a Beta version of the software tool some SMEs and consultants: they have provided structured feedback to define the last prototype version of the software, which is going to be provided to companies and consultants for free through the Italian Compensation Authority (INAIL). Again, the sustainability of such an initiative in different countries from Italy is difficult to predict, which is a limitation of the study: further research developments should tackle this issue, connected with the country-specific networks of parties (i.e., ecosystems). Last but not least, further research on the design, management and impact of dashboards of quantitative indicators for controlling the overall performance of SMEs towards their safety issues would be beneficial.

Author Contributions: Conceptualization, D.D.M., M.G.G., B.M., G.J.L.M., G.P., G.S. and F.T.; Formal analysis, D.D.M., M.G.G., B.M., G.J.L.M., G.P., G.S. and F.T.; Methodology, D.D.M., M.G.G., B.M., G.J.L.M., G.P., G.S. and F.T.; Writing-original draft, D.D.M., M.G.G., B.M., G.J.L.M., G.P., G.S. and F.T.; Writing-review and editing, D.D.M., M.G.G., B.M., G.J.L.M., G.P., G.S. and F.T. All authors have read and agreed to the published version of the manuscript.

Funding: This research was funded by INAIL (Istituto Nazionale per l'Assicurazione contro gli Infortuni sul Lavoro) within the call BRIC 2016/ID29, SOLVO project. The APC was funded by INAIL.

Conflicts of Interest: The authors declare no conflict of interest.

\section{References}

1. Champoux, D.; Brun, J.-P. Occupational health and safety management in small size enterprises: An overview of the situation and avenues for intervention and research. Saf. Sci. 2003, 41, 301-318. [CrossRef]

2. Muller, P.; Julius, J.; Herr, D.; Koch, L.; Peycheva, V.; McKiernan, S. Annual Report on European SMEs 2016/2017. Focus on Self-Employment; European Commission: Luxembourg, 2017.

3. Ansori, N.; Widyanti, A.; Sutalaksana, I.Z. Safety Outcomes in small-size and medium-size metal enterprises in Indonesia: Are they different? In Proceedings of the 2018 IEEE International Conference on Industrial Engineering and Engineering Management (IEEM), Bangkok, Thailand, 16-19 December 2018; pp. $93-97$.

4. Bluff, E. How SMEs respond to legal requirements to provide information, training, instruction and supervision to workers about work health and safety matters. Saf. Sci. 2019, 116, 45-57. [CrossRef]

5. Salguero-Caparrós, F.; Pardo-Ferreira, M.D.C.; Martínez-Rojas, M.; Rubio-Romero, J.C. Management of legal compliance in occupational health and safety. A literature review. Saf. Sci. 2020, 121, 111-118. [CrossRef]

6. Legg, S.; Olsen, K.; Laird, I.; Hasle, P. Managing safety in small and medium enterprises. Saf. Sci. 2015, 71, 189-196. [CrossRef]

7. Masi, D.; Cagno, E. Barriers to OHS interventions in small and medium-sized enterprises. Saf. Sci. 2015, 71, 226-241. [CrossRef]

8. Tremblay, A.; Badri, A. Assessment of occupational health and safety performance evaluation tools: State of the art and challenges for small and medium-sized enterprises. Saf. Sci. 2018, 101, 260-267. [CrossRef]

9. Walters, D.; Wadsworth, E. European Agency for Safety and Health at Work. In Context and Arrangements for Occupational Safety and Health in Micro and Small Enterprises in the EU: SESAME Project; Publications Office: Luxembourg, 2016.

10. Arocena, P.; Nuñez, I. An empirical analysis of the effectiveness of occupational health and safety management systems in SMEs. Int. Small Bus. J. Res. Entrep. 2010, 28, 398-419. [CrossRef]

11. Hasle, P.; Kines, P.; Andersen, L.P. Small enterprise owners' accident causation attribution and prevention. Saf. Sci. 2009, 47, 9-19. [CrossRef]

12. Micheli, G.J.L.; Gnoni, M.G.; De Merich, D.; Sala, G.; Rosso, A.; Tornese, F.; Piga, G.; Malorgio, B. Barriers, drivers and impact of a simplified occupational safety and health management system in micro and small enterprises. Adv. Intell. Syst. Comp. 2018, 791, 81-90. [CrossRef] 
13. Masi, D.; Cagno, E.; Micheli, G.J. Developing, implementing and evaluating OSH interventions in SMEs: A pilot, exploratory study. Int. J. Occup. Saf. Ergon. 2014, 20, 385-405. [CrossRef]

14. Garnica, G.B.; Barriga, G.D.C. Barriers to occupational health and safety management in small Brazilian enterprises. Production 2018, 28. [CrossRef]

15. Wang, Q.; Mei, Q.; Liu, S.; Zhang, J. Analysis of managing safety in small enterprises: Dual-effects of employee prosocial safety behavior and government inspection. BioMed Res. Int. 2018, 2018, 1-12. [CrossRef]

16. Zhang, J.; Mei, Q.; Liu, S.; Wang, Q. Study on the influence of government intervention on the occupational health and safety (OHS) services of small- and medium-sized enterprises (SMEs). BioMed Res. Int. 2018, 1-15. [CrossRef] [PubMed]

17. Hasle, P.; Limborg, H.J. A review of the literature on preventive occupational health and safety activities in small enterprises. Ind. Heal. 2006, 44, 6-12. [CrossRef] [PubMed]

18. MacEachen, E.; The Small Business Systematic Review Team; Kosny, A.; Scott-Dixon, K.; Facey, M.; Chambers, L.; Breslin, C.; Kyle, N.; Irvin, E.; Mahood, Q. Workplace health understandings and processes in small businesses: A systematic review of the qualitative literature. J. Occup. Rehabil. 2010, 20, 180-198. [CrossRef] [PubMed]

19. Cagno, E.; Micheli, G.J.; Masi, D.; Jacinto, C. Economic evaluation of OSH and its way to SMEs: A constructive review. Saf. Sci. 2013, 53, 134-152. [CrossRef]

20. Floyde, A.; Lawson, G.; Shalloe, S.; Eastgate, R.; D'Cruz, M. The design and implementation of knowledge management systems and e-learning for improved occupational health and safety in small to medium sized enterprises. Saf. Sci. 2013, 60, 69-76. [CrossRef]

21. Schulte, P.A.; Cunningham, T.R.; Guerin, R.J.; Hennigan, B.; Jacklitsch, B.L. Components of an occupational safety and health communication research strategy for small- and medium-sized enterprises. Ann. Work Expo. Health 2018, 62, S12-S24. [CrossRef]

22. Nowrouzi-Kia, B.; Nadesar, N.; Casole, J. Systematic review: Factors related to injuries in small- and medium-sized enterprises. Int. J. Crit. Illn. Inj. Sci. 2019, 9, 57-63. [CrossRef]

23. Walker, D.; Tait, R. Health and safety management in small enterprises: An effective low cost approach. Saf. Sci. 2004, 42, 69-83. [CrossRef]

24. Cagno, E.; Micheli, G.J.; Jacinto, C.; Masi, D. An interpretive model of occupational safety performance for small- and medium-sized enterprises. Int. J. Ind. Ergon. 2014, 44, 60-74. [CrossRef]

25. Farina, E.; Bena, A.; Dotti, A. Impact on safety of a preventive intervention in metalworking micro-enterprises. Saf. Sci. 2015, 71, 292-297. [CrossRef]

26. Bianchini, A.; Donini, F.; Pellegrini, M.; Saccani, C. An innovative methodology for measuring the effective implementation of an occupational health and safety management system in the European Union. Saf. Sci. 2017, 92, 26-33. [CrossRef]

27. Tremblay, A.; Badri, A. A novel tool for evaluating occupational health and safety performance in small and medium-sized enterprises: The case of the Quebec forestry/pulp and paper industry. Saf. Sci. 2018, 101, 282-294. [CrossRef]

28. Zocca, R.; Lima, T.M.; Gaspar, P.; Charrua-Santos, F. Kaizen Approach for the systematic review of occupational safety and health procedures in food industries. In Advances in Intelligent Systems and Computing; Springer Science and Business Media LLC: Cham, Switzerland, 2018; Volume 876, pp. 722-727.

29. Fabiano, B.; Currò, F.; Pastorino, R. A study of the relationship between occupational injuries and firm size and type in the Italian industry. Saf. Sci. 2004, 42, 587-600. [CrossRef]

30. Micheli, G.J.; Cagno, E. Dealing with SMEs as a whole in OHS issues: Warnings from empirical evidence. Saf. Sci. 2010, 48, 729-733. [CrossRef]

31. Lehtinen, S. Activities and ways of organizing better occupational health and safety in small workplaces: Special focus on information. Ind. Heal. 2006, 44, 13-16. [CrossRef]

32. Gopang, M.A.; Nebhwani, M.; Khatri, A.; Marri, H.B. An assessment of occupational health and safety measures and performance of SMEs: An empirical investigation. Saf. Sci. 2017, 93, 127-133. [CrossRef]

33. Santos, G.; Barros, S.; Mendes, F.; Lopes, N. The main benefits associated with health and safety management systems certification in Portuguese small and medium enterprises post quality management system certification. Saf. Sci. 2013, 51, 29-36. [CrossRef] 
34. Jaroenroy, T. and Chompunth, C., An alternative integrated occupational health, safety and environmental management system for small and medium-sized enterprises (SMEs) in Thailand. Int. J. Geomate 2019, 17. [CrossRef]

35. Cagno, E.; Micheli, G.J.; Perotti, S. Identification of OHS-related factors and interactions among those and OHS performance in SMEs. Saf. Sci. 2011, 49, 216-225. [CrossRef]

36. Surienty, L. OSH Implementation in SMEs in Malaysia: The role of management practices and legislation. In Proceedings of the Advances in Intelligent Systems and Computing; Springer Science and Business Media LLC: Cham, Switzerland, 2019; Volume 819, pp. 650-671.

37. Diugwu, I.A. Re-Strategising for effective health and safety standards in small and medium-sized enterprises. Open J. Saf. Sci. Technol. 2011, 1, 115-128. [CrossRef]

38. Bonafede, M.; Corfiati, M.; Gagliardi, D.; Boccuni, F.; Ronchetti, M.; Valenti, A.; Marinaccio, A.; Iavicoli, S. OHS management and employers' perception: Differences by firm size in a large Italian company survey. Saf. Sci. 2016, 89, 11-18. [CrossRef]

39. Sinclair, R.C.; Cunningham, T.R.; Schulte, P.A. A model for occupational safety and health intervention diffusion to small businesses. Am. J. Ind. Med. 2013, 56, 1442-1451. [CrossRef]

40. Boustras, G.; Hadjimanolis, A.; Economides, A.; Yiannaki, A.; Nicolaides, L. Management of health and safety in micro-firms in Cyprus-Results from a nationwide survey. Saf. Sci. 2015, 79, 305-313. [CrossRef]

41. Unnikrishnan, S.; Iqbal, R.; Singh, A.; Nimkar, I.M. Safety management practices in small and medium enterprises in India. Saf. Heal. Work. 2015, 6, 46-55. [CrossRef] [PubMed]

42. Jahangiri, M.; Azmon, H.; Daneshvar, A.; Keshmiri, F.; Khaleghi, H.; Besharati, A.; Daneshvar, S.; Hassanipour, S.; Malakoutikhah, M.; Besharati, M. Occupational health problems and safety conditions among small and medium-sized enterprises: A cross-sectional study in Shiraz, Iran. Ann. Glob. Health 2019, 85, 51. [CrossRef]

43. Cantonnet, M.L.; Aldasoro, J.C.; Iradi, J. New and emerging risks management in small and medium-sized Spanish enterprises. Saf. Sci. 2019, 113, 257-263. [CrossRef]

44. Segarra-Cañamares, M.; Villena Escribano, B.; González García, M.; Romero Barriuso, A.; Rodríguez Sáiz, A. Occupational risk-prevention diagnosis: A study of construction SMEs in Spain. Saf. Sci. 2017, 92, 104-115. [CrossRef]

45. Mashwama, N.; Aigbavboa, C.; Thwala, W.D.D. Occupational health and safety challenges among small and medium sized enterprise contractors in South Africa. In Advances in Intelligent Systems and Computing; Springer Science and Business Media LLC: Cham, Switzerland, 2019; Volume 792, pp. 68-76.

46. Dumitrescu, A.; Deselnicu, D.C. Risk assessment in manufacturing SMEs' labor system. Procedia Manuf. 2018, 22, 912-915. [CrossRef]

47. Sun, J.; Liu, C.; Yuan, H. Evaluation of risk management maturity: Measurable proactive indicators suitable for Chinese small and medium-sized chemical enterprises. IOP Conf. Ser. Earth Environ. Sci. 2019, 242, 042006. [CrossRef]

48. Fera, M.; Macchiaroli, R. Appraisal of a new risk assessment model for SME. Saf. Sci. 2010, 48, 1361-1368. [CrossRef]

49. Reinhold, K.; Järvis, M.; Tint, P. Practical tool and procedure for workplace risk assessment: Evidence from SMEs in Estonia. Saf. Sci. 2015, 71, 282-291. [CrossRef]

50. De Merich, D.; Gnoni, M.G.; Malorgio, B.; Micheli, G.J.L.; Piga, G.; Rosso, A.; Sala, G.; Tornese, F. A new model proposal for occupational health and safety management in small and medium enterprises. In 23rd Summer School "Francesco Turco"; Industrial Systems Engineering: Palermo, Italy, 2018; pp. 101-107.

51. Gnoni, M.G.; Saleh, J.H. Near-miss management systems and observability-in-depth: Handling safety incidents and accident precursors in light of safety principles. Saf. Sci. 2017, 91, 154-167. [CrossRef]

Publisher's Note: MDPI stays neutral with regard to jurisdictional claims in published maps and institutional affiliations. 